\title{
EVALUASI ACTION \& RESULT CONTROL DALAM IMPLEMENTASI SISTEM PENGENDALIAN MANAJEMEN USAHA MIKRO KECIL \& MENENGAH (UMKM) RAHMAD DEKORASI DI TULUNGAGUNG
}

\author{
Weni Agustin \\ Jurusan Akuntansi / Fakultas Ekonomi \\ Weniagustinyudis@gmail.com
}

Lyna Yullyana

Jurusan Akuntansi / Fakultas Ekonomi

Lynayullyana1031@gmail.com

\author{
Maulana Rahmad Rofendi \\ Jurusan Akuntansi / Fakultas Ekonomi \\ Vendirahmat71@gmail.com
}

\begin{abstract}
ABSTRAK
In today's globalization era, competition in the business world is getting tougher. A company is generally always required to provide good and quality performance. One of the things that companies need to pay attention to to deliver maximum quality performance is the implementation of a management system that is controlled and properly implemented. The success in managing the management system will influence and increase the work motivation of human resources in the company so that it can affect the performance given by the company. The purpose of this study is that the authors try to analyze the topic of implementing control and outcome control to increase employee motivation. Rahmad decorations, so that the performance given by human resources Rahmad Decoration will also increase. This study used a qualitative approach using interview, observation, and literature study methods. The findings in this study indicate that the management system by Rahmad Decoration is less precise, especially in controlling actions in terms of multiple jobs, purchasing decoration materials, which sometimes occurs cheating by employees, and missing supplies and decoration materials in the warehouse. And in Result control that occurs when the work of a task by employees is neglected and the punishment system is not firm. Therefore, this study provides recommendations for improvements in the application of management systems, especially in the action and control results of Rahmad Decoration, so that the company can obtain maximum performance results and achieve goals.
\end{abstract}


Keyword : Action Control, Result Control, Lack direction, motivational problems, personal limitations, measuring performance, punisment

\begin{abstract}
ABSTRAK
Pada era globalisasi dewasa ini, persaingan di dunia bisnis semakin ketat. Suatu perusahaan umumnya selalu dituntut agar dapat memberikan kinerja yang baik dan berkualitas. Salah satu hal yang perlu diperhatikan perusahaan untuk pencapaian pemberian mutu kinerja yang maksimal adalah mengenai penerapan pengendalian sistem manajemen yang terkendali dan diterapkan dengan baik. Keberhasilan dalam penerapan pengendalian sistem manajemen akan mempengaruhi dan meningkatkan motivasi kerja sumber daya manusia yang ada di dalam perusahaan sehingga secara langsung dapat mempengaruhi kinerja yang diberikan oleh perusahaan. Tujuan dari penelitian ini adalah penulis mencoba untuk menganalisis topik mengenai penerapan action control dan result control untuk meningkatkan motivasi kerja karyawan Rahmad decoration sehingga kinerja yang diberikan oleh sumber daya manusia Rahmad Dekorasi akan ikut meningkat. Penelitian ini menggunakan pendekatan kualitatif dengan menggunakan metode wawancara, observasi, dan studi pustaka. Temuan pada penelitian ini menunjukan bahwa sistem pengendalian manajemen oleh Rahmad Dekorasi kurang tepat sasaran terutama pada action control dalam hal rangkap pekerjaan, pembelian bahan-bahan dekorasi yang terkadang terjadi kecurangan yang dilakukan oleh karyawan, dan persedian maupun bahan-bahan dekorasi di gudang yang sering hilang. Dan pada Result control terjadi waktu pngerjaan suatu tugas oleh karyawan yang dilam-lamakan dan sistem punishment yang tidak tegas. pada Oleh karena itu penelitian ini mencoba memberikan rekomendasi perbaikan dalam penerapan sistem pengendalian manajemen terutama pada action dan result control pada Rahmad Dekorasi, sehingga perusahaan dapat memperoleh hasil kinerja yang maksimal dan mencapai tujuan.
\end{abstract}

Kata Kunci : Action Control, Result Control, Lack direction, motivational problems, personal limitations, measuring performance, punisment

\title{
PENDAHULUAN
}

Di dunia bisnis, sistem pengendalian manajemen memainkan peran penting yang membuat going concern perusahaan tetap berjalan pada era lingkungan yang tidak pasti. Perubahan lingkungan internal dan eksternal yang memiliki dampak besar pada dunia bisnis saat ini. Pentingnya management control system sebuah sistem yang digunakan untuk mengumpulkan dan menggunakan informasi untuk mengevaluasi kinerja dari sumber daya yang ada contohnya manusia, mesin, keuangan dengan tetap melihat strategi perusahaan.(Rosanas, 2011) Perencanaan merupakan salah satu proses yang terpenting didalam operasi organisasi, karena merupakan panduan arah pelaksanaan aktivitas kerja organisasi. Anggaran menunjukkan perolehan dan penggunaan sumber-sumber organisasi dalam kurun waktu tertentu (Rachmad Gesah Mukti Prabowo, 2020). Dalam dunia bisnis 
kecil perlu diterapkannya SPM, pengendalian manajemen yang diaplikasikan dalam rangka menetapkan tujuan dan dapat memberikan suatu motivasi orang dalam perusahaan. Dalam suatu perusahaan sumber daya manusia memegang peranan yang sangat penting. Sumber daya manusia merupakan fondasi dasar bagi perusahaan. Jika perusahaan tidak dapat mengelola sumber daya manusianya dengan baik maka perusahaan tidak dapat berdiri dengan kokoh dan mudah untuk jatuh. Menurut Merchant dan Van der Stede pada (Handi dan Imanuel, 2013) terdapat 3 masalah dasar yang dalam pengendalian yaitu lack of direction adalah kondisi dimana para pekerja tidak mengetahui apa yang diinginkan oleh perusahaan, motivational problems yaitu pekerja mengetahui apa yang diinginkan perusahaan tetapi tidak melaksanakannya karena adanya perbedaan dengan kepentingannya sendiri, dan personal limitations yaitu dimana para pekerja mengetahui apa yang diinginkan perusahaan, memiliki motivasi yang tinggi tetapi tidak mampu melaksanakannya karena kemampuannya yang terbatas.

Pelaku bisnis khususnya UMKM memiliki peran penting dalam sistem ekonomi lingkup nasional, yaitu memperkuat struktur ekonomi nasional dengan cara antara lain meningkatkan pendapatan per kapita masyarakat, pemerataan lapangan kerja, menyumbangkan devisa. UMKM di Indonesia sendiri memberikan sumbangan terhadap PDB Indonesia sebesar 9.90\% dan menyerap tenaga kerja sebanyak 107.657 .509 orang pada tahun 2012 data BPS tahun 2012 pada (Handi dan Imanuel, 2013). Dan Di Tulungagung Jumlah UMKM juga termasuk banyak. Lihat table :

Perkembangan UMKM di Kabupaten Tulungagung, 2014-2018

\begin{tabular}{|c|c|c|c|c|c|}
\hline Uraian & 2014 & 2015 & 2016 & 2017 & 2018 \\
\hline Jumlah UMKM (Unit) & 44633 & 48650 & 51569 & 53488 & 57897 \\
\hline Modal Usaha (000 Rp) & 1070546350 & 1166895522 & 1236909253 & 1274016530 & 1375949718 \\
\hline Volume Usaha (000 Rp) & 1348189255 & 1469526288 & 1557697865 & 1679275119 & 1817105969 \\
\hline Jumlah karyawan (Unit) & 233085 & 233085 & 247070 & 261055 & 280065 \\
\hline
\end{tabular}

Dalam penelitian ini menggunakan objek salah satu UMKM di Tulungagung yaitu Rahmad Dekorasi. Usaha jasa dekorasi pada abad ini mengalami perkembangan yang cukup pesat dan diminati para pelaku usaha karena memiliki peluang yang cukup menjanjikan termasuk di kota-kota kecil seperti Tulungagung. Rahmad Dekorasi adalah lembaga atau badan yang khusus melayani jasa dibidang pernikahan, yang secara pribadi membantu calon 
pengantin mempersiapkan segalanya yang berhubungan dengan dengan acara sakral pernikahan agar berjalan lancar sesuai dengan yang diinginkan. Rahmad Dekorasi juga membantu mengkoordinasikan konsep pernikahan, membantu mengestimasi budget pernikahan dan mengatur jalanya prosesi pernikahan sehingga acara pengantin dapat berjalan dengan maksimal.

Pada penelitain yang dilakuakan oleh Handi Wijaya dan Imanuel Goestaman UKM Griya Karya Tiara Kusuma di Surabaya Peneliti menemukan bahwa terdapat kendalakendala dalam implementasi Sistem Manajemen Lima Jari-Jari. Berbagai kendala tersebut, diantaranya seperti kurangnya koordinasi antara atasan dan karyawan, pekerjaan tidak tepat waktu, tidak ada standar kualitas yang ditetapkan oleh pemilik, terjadinya stockout pada persediaan bahan baku dan overstock pada produk jadi serta kurangnya pengetahuan karyawan. Dan dalam penelitaian ini penulis memberikan saran Pengukuran kinerja dilakukan dimulai dari pemanfaatkan bahan baku dalam hal menjaga kualitas produk. Untuk hasil penjualan perlu dilakukan perhitungan dan analisis sebagai perbandingan tiap periode yang dihasilkan dan Perlunya penetapan target untuk mendorong dan meningkatkan motivasi karyawan / mengatasi motivational problems dengan adanya kesadaran mengenai tujuan yang harus dicapai. Selain itu dengan adanya target karyawan dapat memonitor kinerjanya sendiri sehingga dapat memenuhi tujuan yang ingin dicapai(Handi dan Imanuel, 2013).

\section{LANDASAN TEORI}

\section{Pengertian Sistem Pengendalian Manajemen}

Menurut pendapat Anthony \& Govindarajan pada (Wijaya, 2018) istem pengendalian manajemen merupakan suatu sistem untuk mengukur kinerja agar dapat mengendalikan semua sumber daya internal dengan efektif dan dapat mencegah terjadinya tindakan penyimpangan dari tujuan badan usaha

\section{Masalah-masalah Pengendalian}

Sistem pengendalian manajemen dapat menyelesaikan tiga masalah utama dari para anggota sebuah badan usaha, yaitu: lack of direction, motivational problems, dan personal limitations. Lack of direction atau tidak tahu terjadi karena karyawan tidak mengetahui apa yang diharapkan oleh perusahan untuk mereka lakukan sehingga tidak dapat berkontribusi dengan dengan baik untuk memenuhi tujuan yang dimiliki badan usaha. Masalah yang kedua 
yaitu motivational problems atau tidak mau, muncul apabila karyawan telah memahami apa yang diharapkan untuk mereka lakukan tetapi tujuan antara karyawan dan perusahaan tidak selaras sehingga karyawan bertindak sesuai dengan keinginannya sendiri dan mengabaikan kepentingan badan usaha. Masalah yang terakhir adalah personal limitations atau tidak mampu terjadi ketika karyawan mengetahui dan memahami tujuan badan usaha, akan tetapi mereka tidak mampu melakukannya dengan baik karena ada beberapa keterbatasan lain sehingga kinerja yang dihasilkan tidak dapat maksimal.

\section{Bentuk-bentuk Sistem Pengendalian Manajemen}

Bentuk yang pertama, result controls merupakan bentuk pengendalian untuk mengendalikan perilaku karyawan pada berbagai tingkat dalam badan usaha dengan menyediakan reward dan punishment atas pekerjaan yang dilakukan. Kedua, action controls merupakan pengendalian untuk memastikan bahwa tindakan yang dilakukan karyawan selama proses operasional bermanfaat atau sesuai dengan tujuan badan usaha. Ketiga, personnel control merupakan pengendalian yang dilakukan dengan membangun dan menanamkan kesadaran karyawan untuk melaksanakan tugasnya. Yang terakhir adalah cultural control dirancang untuk menciptakan lingkungan sosial yang mendorong karyawan untuk berperilaku sesuai dengan norma dan nilai yang ada pada badan usaha.

\section{Action control}

Menurut Merchant \& Stede, pada (Wijaya, 2018) Action control merupakan pengendalian yang kita lakukan dari awal proses hingga akhir suatu proses dalam kegiatan suatu organisasi, agar proses yang sedang berlangsung sesuai dengan aturan atau ketentuan. Action control memiliki empat bentuk dasar, yaitu behavioral constrains, preaction review, action accountability dan redundancy.

\section{Behavioral Constraint}

Constrains dibagi menjadi dua bentuk yaitu physical dan administrative. Physical contraints digunakan untuk mencegah karyawan melakukan kecurangan atau tindakan yang akan menyebabkan kerugian fisik bagi badan usaha. Sedangkan, administrative constrains bertujuan membatasi kemampuan karyawan untuk melakukan semua atau hanya sebagian dari tugas atau tindakan tertentu agar tidak melakukan tindakan yang dapat merugikan badan usaha. Banyak badan usaha menggunakan beberapa bentuk dari pembatas fisik, termasuk kata sandi pada komputer, dan batas akses terhadap suatu area di mana barang berharga dan 
informasi penting disimpan. Secara administratif, dapat dilakukan dengan cara melakukan pemisahan fungsi

\section{Preaction Reviews}

Preaction reviews merupakan peninjauan kembali terhadap rencana sebelum sebuah rencana mulai dilaksanakan. Pengendalian ini membutuhkan komunikasi dua arah antara atasan dan para bawahannya. Setiap akan melakukan aktivitas, para atasan akan memantau apa yang akan dilakukan dan memberikan masukan apabila ada yang kurang.

\section{Action Accountability}

Cara pengendalian ini adalah membuat kesepakatan atau aturan dalam organisasi bahwa seseorang harus bertanggungjawab atas hal-hal yang telah ditetapkan. Hal ini dilakukan ada yang bertanggung jawab terhadap fungsi tertentu dan memastikan proses yang dilakukan berjalan sesuai dengan yang diharapkan oleh perusahaan. Langkah - langkah yang dilakukan untuk menerapkan pengendalian ini adalah:

1. Mendefinisikan dengan jelas tindakan apa yang dapat diterima oleh perusahaan dan tidak dapat diterima oleh perusahaan.

2. Mengkomunikasikan hal tersebut kepada seluruh elemen perusahaan.

3. Observasi atau pelacakan tentang apa yang sebenarnya terjadi.

4. Pemberian reward atas tindakan baik yang dilakukan oleh karyawan danpunishment atas tindakan karyawan yang tidak benar.

\section{Redundancy}

Redudancy adalah pengendalian yang dilakukan apabila ada keraguan dari atasan untuk menyerahkan sebuah tugas kepada salah satu karyawan, sehingga untuk mengatasi hal ini atasan akan memberikan pekerjaan yang sama kepada dua/lebih orang. Redudancy ini biasa dilakukan oleh perusahaan ketika ada staff baru yang masuk. Ketika para staff baru masuk, biasanya akan ada senior yang mendampingi. Hal ini dilakukan untuk memastikan bahwa pekerjaan yang dikerjakan oleh staff baru tersebut dapat terlaksana dengan baik.

Bentuk pengendalian yang ada, tidak dapat berdiri sendiri-sendiri melainkan harus dikombinasikan agar menjadi sebuah pengendalian yang benar-benar dapat mengendalikan sumber daya manusia yang ada di perusahaan.

\section{Pengetian Result Control}

Result control merupakan pengendalian yang berfokus pada hasil yang diperoleh dari tindakan-tindakan yang diambil oleh karyawan pada berbagai level organisasi (Satria, 2018). 
Result control merupakan sebuah bentuk pengendalian tidak langsung (indirect form of control) karena tidak secara eksplisit berfokus pada tindakan karyawan. Sistem yang digunakan pada result control biasanya disebut pay for performance, yaitu pemberian reward untuk karyawan atas kinerja yang baik atau punishment bagi karyawan dengan kinerja buruk.

\section{Tahapan penerapan Result Control}

Menurut Merchant dan Van der Stede pada (Satria, 2018) penerapan result control dalam organisasi terdapat 4 tahap sebagai berikut yaitu, Mendefinisikan dimensi hasil yang diinginkan atau tidak (defining performance dimensions), Penilaian kinerja dan dimensi tersebut (measuring performance) untuk bisa melakukan sebuah evaluasi dalam result control sebuah organisasi harus dapat melakukan pengukuran kinerja dari para karyawan, Menyusun kinerja yang harus dicapai pekerja (setting target atau standar harus ditetapkan untuk setiap performan targets) dimensions yang ada dalam organisasi, Menyediakan reward and punishment (providing rewards and punishment).

\section{Reward system}

Suatu sistem yang digunakan untuk mendistribusikan penghargaan kepada karyawan dalam badan usaha. Penilaian kinerja merupakan suatu bentuk pengendalian dari manager dalam mengendalikan perilaku individu dalam organisasi agar mendukung pencapian tujuan organisasi. Oleh karena itu pihak organisasi diharapkan dapat menciptakan ukuran kinerja yang tepat dan melakukan penilaian yang sesuai sehingga dapat memaksimalkan kinerja dari masing-masing karyawan dalam organisasi. Menurut Kreitner dan Kinicki,pada (Satria, 2018) terdapat 3 kriteria reward yaitu performance result, performance action and behavior, dan nonperformance consideration.

\section{Sistem penilaian kinerja}

Kinerja merupakan hal yang sangat penting dan harus diperhatikan oleh seluruh manajemen, baik pada tingkatan organisasi kecil maupun besar. Hasil kerja yang dicapai oleh organisasi atau karyawan adalah bentuk pertanggungjawaban kepada organisasi. Kinerja biasanya dirasakan sebagai pencapaian tujuan organisasi, jelas bahwa harus ada tumpeng tindih yang signifikan antara pengukuran kinerja dan sistem pengendalian manajemen. Kedua sistem memiliki tujuan akhir yang sama dalam mendukung pencapaian tujuan organisasi. 


\section{METODE PENELITIAN}

Penelitian ini merupakan sebuah penelitian yang bersifat explanatory research, dimana dijelaskan mengenai penerapan dari action dan result control pada badan usaha. Penelitian ini bertujuan mendeskripsikan hubungan antara badan usaha dengan sistem pengendalian manajemen untuk mengatasi control problem yang terjadi pada Rahmad Dekorasi di Tulungagung. Metode pengumpulan data yang digunakan pada penelitian ini adalah wawancara, observasi dan analisis dokumen. Wawancara dilakukan dengan pihakpihak yang bersangkutan dan memiliki kemampuan untuk memberikan data dan informasi yang dapat membantu peneliti dalam menjawab research question. Wawancara dilakukan secara langsung (tatap muka) dengan metode yang digunakan adalah semi structured interview dan terlebih dahulu dilakukan perjanjian waktu terhadap responden. Observasi yang dilakukan peneliti sebagai pengamat murni (observer) untuk mengamati dari dekat dan memperoleh data dari aktivitas operasional yang dilakukan objek penelitian. Dilakukan juga analisis dokumen yang ada pada Rahmad Dekorasi, sebagai pendukung dalam melakukan penelitian. Hal ini dilakukan untuk melihat konsistensi dari data yang diberikan oleh partisipan dan hasil observasi tidak mengalami perubahan.

\section{HASIL DAN PEMBAHASAN}

\section{Gambaran Umum Perusahaan}

Rahmad Dekorasi merupakan salah UMKM di Tulungagung yang bergerak di bidang jasa dekorasi sebuah acara pernikahan, maupun acara formal lainnya. Rahmad Wedding Decoration didirikan pada bulan November 2017. Memiliki 19 karyawan yang dibagi-bagi menjadi beberapa bagian

1. Administrasi

2. Bagian Penata Panggung 2 orang

3. Bagian memasang Property 3 orang

4. Bagian menata Bunga 3 Orang

5. Bagian kurir truk dan sopir truk 4 orang

6. Bagian pemasang Slayer 4 orang

7. Bagian mengukir kayu property 2 orang

Implementasi Action dan Result control pada Rahmad Wedding Decoration di Tulungagung 
Pada bagian ini akan dijelaskan mengenai implementasi action control dan result control yang mengakibatkan terjadinya problem pada Rahmad Dekorasi.

\section{Action Control}

Pada bagian ini akan dibahas kelemahan action control yanga ada pada Rahmad Dekorsi. Yang pertama, lemahnya behavioral contrains dalam administrative constrains yang sangat minim sehingga tidak ada batasan yang diberikan, terutama kepada staff Administrasi yang terkadang di suruh untuk menemui calon klien untuk menawarakan paketpaket dekorasi pernikahan. Karena keterbatasan pengetahui Admin dalam masalah masalah paket-paket dekorasi tersebut calon klien tidak jadi bekerjasama karena kurang puas dengan penjelasan-penjelasan yang diberikan admin. Dan juga terjadi dibagian karyawan ukir kayu dekorasi, yang biasnya disuruh untuk membeli kebutuhan untuk ukir sendiri. Ternyata sering kejadian harga di toko tidak sama dengan harga nota yang di setorkan ke Admin. Batasan untuk seluruh karyawan terhadap bahan dan inventory juga sangat minim sehingga terjadi kehilangan bahan baku pada gudang seperti cat kayu, lampu-lampu dekorasi terkadang juga bunga dekorasi. Untuk Preaction Reviews tidak terjadi kedala kareana onwer selalu melakukan meeting 2 minggu sebelum acara dilaksanakan dengan para karyawannya. Onwer akan memberikan arahan kepada karyawan setiap bagian-bagiannya atas gambaran dekorasi yang sesuai permintaan client. Action accountability untuk pelaksanaan sudah baik karena onwer memberikan aturan-aturan apa yang boleh dilakuakan karyawan dan apa yang tidak boleh dilakukan karyawan. Dan untuk Redundancy di Rahmad wedding decoration sudah berjalan dengan baik karane setiap karyawan baru akan di dampingi oleh karyawan lama untuk memastikan pekerjaan berjalan sesuai ketentuan.

\section{Result Control}

Pada bagian ini akan dibahas result control yang ada pada Rahmad Wedding Dekoration. Yang pertama, defining performance dimensions yang diterpakan dengan menilai produktifitas karyawan dan bagaimana karyawan melaksanakan pekerjaannya pada kondisi apapun (ramai atau sepi) sehinngga dapat memenuhi kepuasan client pengguna jasa ini. Yang kedua, measuring performance yang yang diterapkan pada usaha dengan melihat kedisiplinan karyawan yang kemauan dan komitmen karyawan dalam menjalankan tugasnya. Pada control ini terjadi sedikit kendala pada bagian pengukir kayu untuk properti dekorasi, pengerjaan tugas yang dibuat lebih lama dari target penyelesaian. Yang ketiga setting performance targets telah menentukan target dimana para karyawan diharapkan dapat mendisagn decoration sesui keingan konsumen yang telah disampaikan oleh owner. 
Yang terakhir dari result control yaitu providing reward or punishment. Ada sistem reward yang diberikan kepada karyawan jika bekerja dengan hasil yang memuaskan maupun jiaka perusahaan dapat mencapai goals penjualan pertahun, reward yang diberikan berupa bonus uang. Untuk sistem punishment dirasa masih kurang berjalan dengan baik karena masih sering terjadi kesalahan dan kecurangan yang dilakukan oleh karyawan karena sistem punishment pada badan usaha tidak tegas dan jelas.

\section{Penyebab dan Dampak Adanya Control Problem pada Rahmad Dekoration di Tulungagung.}

1. Lack of direction

Lack of direction yang terjadi dibagian action control pada behavioral contrains dalam administrative constrains tidak ada batasan yang diberikan, terutama kepada staff Administrasi yang terkadang di suruh untuk menemui calon klien untuk menawarakan paket-paket dekorasi pernikahan. Karena keterbatasan pengetahui Admin dalam masalah masalah paket-paket dekorasi tersebut calon klien tidak jadi bekerjasama karena kurang puas dengan penjelasan-penjelasan yang diberikan admin. Merangkap memiliki keuntungan untuk mendapatkan sebuah pengalaman dan persepsi baru terhadap pekerjaan lain, namun juga dapat menghambat atau memperlambat kinerja karyawan itu sendiri, seperti beberapa pekerjaan yang selesai tapi tidak berkualitas justru mungkin tidak berdampak baik pada citra Rahmad Dekorasi. Susahnya menentukan skala prioritas pekerjaan mana terlebih dahulu yang harus dikerjakan juga menghambat kinerja karyawan yang memiliki pekerjaan lebih dari satu diluar jabatannya. Masalah ini akan menimbulkan dampak bagi kelangsungan usaha yaitu tidak dapat tercapainnya goals usaha yang telah ditargetkan.

2. Motivational problems

Motivational problems yang terjadi pada action control pada behavioral contrains dimana dibagian karyawan ukir kayu dekorasi, yang biasnya disuruh untuk membeli kebutuhan untuk ukir sendiri. Ternyata sering kejadian harga di toko tidak sama dengan harga nota yang di setorkan ke Admin. Dampak yang ditimbulkan kerugian keuangan pada usaha karena karyawan akan dengan mudah melakukan kecurangan-kecuranganterhadap badan usaha.

3. Personal Limitations 
Personal Limitations yang terjadi pada action control pada behavioral contrains dimana batasan untuk seluruh karyawan terhadap bahan dan inventory juga sangat minim sehingga terjadi kehilangan bahan persediaan pada gudang seperti cat kayu, lampu-lampu dekorasi terkadang juga bunga dekorasi disebabakan karena tidak adanya sistem invetory yang baik. Dampak yang ditimbulkan akan berpengaruh pada kinerja keuangan dan kelangsungan hidup badan usaha karena telah kehilangan barang-barang persedian.

\section{Penyebab dan Dampak Adanya Result Problem pada Rahmad Dekorasi di Tulungagung.}

1. measuring performance yang yang diterapkan pada Rahmad Dekorasi kedisiplinan karyawan yang kemauan dan komitmen karyawan dalam menjalankan tugasnya. Pada control ini terjadi sedikit kendala pada bagian pengukir kayu untuk properti dekorasi, pengerjaan tugas yang dibuat lebih lama dari target penyelesaian penyebab karena owner menggunakan sistem gaji bedasarkan waktu yaitu berapa hari pengerjaan melebihi target. Akibatnya biaya gaji yang dikeluarkan untuk upah karyawan bagian ukir akan membengkak tidak sesuai dengan anggaran yang telah disiapkan sebelumnya.

2. Untuk sistem punishment dirasa masih kurang berjalan dengan baik karena masih sering terjadi kesalahan dan kecurangan yang dilakukan oleh karyawan karena sistem punishment pada badan usaha tidak tegas dan jelas. Karyawan akan melakukan kesalahan dan kecurangan berulang-ulang

\section{Rekomendasi Pembenahan pada Action Control}

1. Penulis membeikan dua saran untuk maslah rangkap jabatan.

1) Yang pertama, sering mungkin owner mengajak/mendampingi staff administrasi bertemu calon klien supaya staff admin bisa belajar dan memahami paket apa saja yang bisa ditawarkan ke calon client. Dan bagaimana cara kita meyakinkan calon client supaya yakin akan produk yang akan mereka gunakan.

2) solusi yang kedua yaitu menambambahkan karyawan baru jika memang owner sudah kewalahan menangani klien sendirian tetapi perlu mempertimbangakan keuangan dalam perusahaan masih mampu tidak untuk menggaji karyawan baru karena merekut karyawan baru berarti akan ada 
penambahan pengeluaran baru diawal..Dan owner perlu mempertimbangkan bagaimana perkembangan perusahaan dalam satu tahun kedepan dengan adanya penambahan karyawan baru. Jika ada karyawan maka tugas owner juga akan lebih mudah dan goals tahuanan dapat tercapai.

2. Saran yang dapat peneliti berikan adalah Untuk mengatasi kecurangan atas pembelian bahan-bahan Dekorasi sebaiknya owner membuat sebuah aturan dimana pembelanjaan baik sedikit maupu banyak hanya bisa di lakukan oleh pihak administrasi saja, uaang yang keluar dari kas hanya atas seizin owner. Dan owner pun harus rajin mengecek setiap transaksi keluar masuk untuk mengantisipasi kecurangan lagi.

3. Sebaiknya owner memulai untuk mengelola stok barang di gudang, pastikan menugaskan satu orang khusus yang bertanggung jawab dalam melakukan segala jenis pencatatannya, seperti mencatat stok yang masuk dan keluar. Setelah mengumpulkan data input dan output barang, langkah selanjutnya yang harus owner lakukan adalah membuat forecast atau perkiraan persediaan stok barang berupa berapa jumlah persediaan yang dibutuhkan pada periode ini. Pencatatan persediaan secara rutin dilakukan setiap ada barang yang masuk, pindah tempat, dan barang keluar. Selanjutnya melakukan stok opname secara berkala sesuai kebutuhan untuk membantu dalam melakukan manajemen stok barang di gudang. Stock Opname merupakan proses berkala yang dilakukan untuk menghitung fisik barang dagangan dan persediaan yang sebenarnya dimiliki oleh sebuah bisnis, yang lalu kemudian hasilnya tersebut dibandingkan dengan jumlah yang ada di dalam catatan persediaan.

\section{Rekomendasi Pembenahan pada Result Control}

1. Pada bagian pengukir kayu untuk properti dekorasi, pengerjaan tugas yang dibuat lebih lama dari target penyelesaian penyebab karena owner menggunakan sistem gaji bedasarkan harian. Solusi penulis, jika karyawan bisa diajak diskusi maka ajak karyawan diskusi masalah gaji mereka mau dibuat harian atau borongan saja agar sama-sama di utungkan. Jika memang gaji dari harian sedikit kecil maka owner juga harus siap menambah sedikit lagi. Tapi dengan perjanjian karyawan harus konsisten harus mampu mengerjakan sesuai batas target. Tetapi jika memang karyawan tidak ada perubahan, silakan diganti saja dengan karyawan baru.

2. Sistem reward yang diberikan pada owner sudah cukup baik dan untuk rekomendasi sistem reward dan punishment yang tegas untuk seluruh karyawan agar karyawan 
melakukan tindakan yang diinginkan sesuai dengan tujuan badan usaha. Contohnya pemberiaan hukum yang tegas kepada karyawan yang melakukan kecurangan berupa pemotongan gaji sesuai kerugian dan pemutusan hubungan kerja.

\section{KESIMPULAN}

1. Temuan dalam penelitian ini dapat dikategorikan ke dalam tiga jenis masalah pengendalian yaitu lack of directions, motivational problems, personal limitations. Rahmad Dekorasi memiliki permasalahan tersebut pada action dan result control yang telah diterapkan. Permasalahan tersebut muncul karena dipicu oleh lemahnya desain sistem pengendalian yang dimiliki badan usaha yang mengakibatkan kinerja karyawan kurang maksimal dan sering terjadi kecurangan.

2. Kelemahan yang sering terjadi dibagian action control pertama tidak ada Batasan yang diberikan kepada staff admin yang disuruh untuk menemui calon client. Serta kecurangan harga pada pembelian bahan baku yang dilakukan oleh karyawan, dan tindakan kecuranagn pada bagian gudang badan usaha.

3. Untuk permasalahan result control untuk bagian measuring performance dimana karyawan bagian pengukir kayu untuk properti dekorasi, pengerjaan tugas yang dibuat lebih lama dari target penyelesaian dan sistem punishment yang kurang tegas dan owner sehingga sering terjadi kecurangan.

4. Rekomendasi perbaikan dari action control pada Rahmad Dekorasi yang pertama terkait masalah rangkap jabatan sebaiknya owner melakukan pendampingan dan pelatiahann terlebih dahulu kepada staff admin jika memang harus juga diberi tanggungjawab memenumui calon client, agar staff paham betul apa yang harus dilakukannya ataupun penambahan karyawan baru agar mendapat hasil yang maksimal, rekomendasi yang kedua pada pemeblian bahan-bahan dekorasi harus dilakukan oleh admin tidak boleh karyawan agar tidak ada tidak kecuranagan, rekomendasi yang ketiga terkait masalah hilangnya persedian dekorasi di gudang yaitu melakukan pencatatan barang yang keluar masuk gudang sendiri maupun ditanggungjawabkan kepada orang kepercayaan dan melakukan pengecekan persediaan secara bersekala. Rekomendasi result control untuk karyawan bagian pengukir kayu untuk properti dekorasi pengerjaan tugas yang dibuat lebih lama dari target mak, tanya langsung mau dibuat sistem gaji harian atau borongan. Agar sama- 
sama mengutungkan kedua belah pihak dan rekomendasi untuk sistem punismentnya dibuat kejelesan peraturan yang ada dan dipertegas.

\section{DAFTAR PUSTAKA}

Handi dan Imanuel. (2013). Action \& result control. : : Jurnal Ilmiah Mahasiswa, 2(2), 120.

Rachmad Gesah Mukti Prabowo. (2020). EVALUASI AKUNTABILITAS RENCANA KERJA DAN ANGGARAN. Jurnal Ekonomi \& Manajemen, 11(1), 25-34.

Rosanas, J. M. (2011). Working Paper WP-891 FAIRNESS, JUSTICE, SUBJECTIVITY, OBJECTIVITY AND GOAL CONGRUENCE IN MANAGEMENT CONTROL SYSTEMS Natàlia Cugueró. 3. Retrieved from http://ssrn.com/abstract=2079604

Satria, T. Y. (2018). ANALISIS PENERAPAN RESULT CONTROL DALAM UPAYA MENINGKATKAN KINERJA PERSONAL TRAINER PADA FORTON. Jurnal Ilmiah Mahasiswa, 7(1), 393-406.

Wijaya, P. B. (2018). PENERAPAN ACTION DAN RESULT CONTROL UNTUK MENGATASI CONTROL PROBLEM. Jurnal Ilmiah Mahasiswa, 7(2), 1-20. 